\title{
EL SACRIFICIO ENTRE EL DEPORTE Y LA CLASE SOCIAL EN UN EQUIPO DE NADADORES MASTER
}

\author{
O SACRIFÍCIO ENTRE O ESPORTE E A CLASSE SOCIAL EM UMA EQUIPE DE \\ NADADORES MÁSTER
}
SACRIFICE BETWEEN SPORTS AND SOCIAL CLASS IN A MASTER SWIMMING TEAM

Julia Hang*

Palabras clave:

Sacrificio.

Clase social.

Deportes.

Natación.

\begin{abstract}
Resumen: El presente artículo se propone analizar los diversos sentidos que un grupo de nadadores master otorgan a la noción nativa de sacrificio y los modos en que, a través de ella, se configuran moralidades y prácticas específicas. Se buscará profundizar en la especificidad del caso de la natación master, donde las representaciones se encuentran atravesadas no sólo por las dimensiones económicas y corporales, sino que juega un rol fundamental la dimensión etaria. Prestando especial atención a los modos en que, a partir del trabajo y del esfuerzo corporal, los nadadores incorporan una ética del sacrificio que da cuenta de un universo moral particular, a través del cual se construyen fronteras simbólicas y distinciones sociales que nos permitirán preguntar por el modo en que el sacrificio opera como particularidad de clase en la práctica deportiva de este grupo en particular.
\end{abstract}

Palavras- chave: Sacrifício.

Classe social.

Esportes.

Natação.
Resumo: 0 presente artigo se propõe a analisar os diversos sentidos que um grupo de nadadores máster concede à noção nativa de sacrifício e os modos em que através dela se configuram moralidades e práticas específicas. Buscar-se-á aprofundar a especificidade do caso da natação máster, em que as representações se encontram permeadas não apenas pelas dimensões econômicas e corporais, mas também pela dimensão etária, que exerce um papel fundamental. Será dada especial atenção à maneira como, a partir do trabalho e do esforço corporal, os nadadores incorporam uma ética do sacrifício que dá conta de um universo moral particular. Nesse universo se constroem fronteiras simbólicas e distinções sociais que nos permitirão perguntar pelo modo em que o sacrifício opera como particularidade de classe na prática esportiva desse grupo particular.

Abstract: This article analyzes the distinct meanings ascribed by a group of master swimmers to the native notion of sacrifice and the ways moralities and specific practices are set through it. It will look further into the particular case of master swimming, where representations are crossed not only by economic and physical dimensions, but also by age. It pays particular attention to the ways in which swimmers, through work and physical effort, incorporate an ethic of sacrifice that accounts for a particular moral universe, through which symbolic boundaries and social distinctions are built that enable us to ask about the way sacrifice operates as a class sign in the sport practice of that particular group.
*Facultad de Humanidades y Ciencias de la Educación de UNLP. La Plata, Argentina.

E-mail: juliahang@ @otmail.com

Recebido em: 05-05-2016 Aprovado em: 02-06-2017

(c) (i) () Licence 


\section{INTRODUCCIÓN Y CONSIDERACIONES METODOLÓGICAS}

En el año 2011, cuando realicé mi tesina de grado sobre los master', inicié un camino de investigación en los estudios sociales del deporte, con el objetivo de pensar los modos de sociabilidad de las clases medias de la ciudad de La Plata ${ }^{2}$ a partir del estudio de sus prácticas deportivas, analizando específicamente el caso de la natación master. De la mano del método etnográfico, y dejándome llevar por los caminos que los actores en el campo me han ido señalando, el objeto fue cambiando y redefiniéndose. Del mismo modo, mis preocupaciones iniciales y mis hipótesis en torno al tema se han ido reformulando. Sin embargo, a lo largo de este recorrido los términos que aparecían en la definición inicial del objeto de investigación parecen seguir siendo fundamentales en dicho campo. Los conceptos de sociabilidad, deporte y clase media emergen constantemente, adquiriendo contenidos específicos a lo largo del trabajo de campo. En este contexto, la noción nativa de sacrificio se nos presenta como un disparador para pensar las relaciones entre dichas categorías, en tanto que los sentidos construidos en torno a ella nos permitirían pensar las conexiones que existieran entre el sacrificio como condición y característica de la práctica deportiva y las representaciones de ciertos sectores de las clases medias platenses. Así, partiendo de algunas inquietudes en torno a la noción de sacrificio que en conjunto elaboramos con Branz (HANG; BRANZ 2014), aquí se abordarán especíicamente los sentidos que la noción de sacrificio adquiere para los nadadores master del Club Unidos de La Plata (de ahora en más referido como CULP), retomando algunos de los interrogantes que en aquella oportunidad planteamos: ¿qué implica sacrificarse para los sujetos investigados?, ¿por qué se sacrifican?, ¿se obtienen beneficios por sacrificarse?, ¿quiénes son los que no se sacrifican?, ¿cuáles son las clasificaciones morales que se producen y reproducen a partir de la idea de sacrificarse o no sacrificarse que desbordan la práctica específica?

Ubicada en las afueras de la ciudad de La Plata, en el barrio residencial de Gonnet, se encuentra una de las tres sedes del tradicional Club Unidos de La Plata. Fundado en el año 1937, como una fusión entre un grupo de la división de rugby del club Gimnasia y Esgrima de La Plata y el Colegio Nacional de La Plata, desde sus orígenes la pertenencia al club estaba restringida a estudiantes universitarios y profesionales egresados de la Universidad Nacional de La Plata, restricción que con el correr de los años y ante la pérdida significativa de socios a partir de la década del '90, se ha ido flexibilizando. Las otras sedes se encuentran en Punta Lara, bordeando el río, donde tienen lugar las actividades náuticas, y en el centro de la ciudad.

Es en Gonnet donde se encuentran tanto la pileta climatizada de 25 metros donde entrena el equipo de natación master la mayor parte del año, como la pileta olímpica de 50 metros de largo, al aire libre, donde tiene lugar el entrenamiento durante el verano cuatro veces por semana.

Los master del CULP conforman un equipo de aproximadamente 60 nadadores, cuyas edades varían entre los 20 y 80 años $^{3}$. Entrenados por Pablo y Mario, entre ellos encontramos

\footnotetext{
1 En el presente texto las cursivas serán utilizadas para destacar los términos significativos desde el punto de vista nativo, cuyo sentido será desagregado en cada caso. El mismo criterio será usado para transcribir fragmentos de entrevistas que serán a su vez entrecomillados.Vale la pena aclarar aquí, que la natación para masters es una disciplina competitiva orientada a personas mayores de 20 años y sin límite de edad, en la cual las categorías se dividen cada 5 años, siendo pre-master aquellos que tienen entre 20 y 25 años, categoría $A$ los que tienen entre 25 y 30 , categoría B de 30 a 35 años y así sucesivamente. A su vez, se separa en masculino y femenino.

2 La ciudad de La Plata es la ciudad capital de la Provincia de Buenos Aires, Capital de Argentina.

3 Si bien por una cuestión de espacio no reflexionaré aquí sobre mi(s) rol(es) en el campo, sí vale la pena mencionar que fui miembro tanto del equipo de natación master, al mismo tiempo que poseía un cargo menor en la comisión directiva del club. Esta doble pertenencia, como investigadora y miembro del grupo social estudiado lejos de ser una limitación me ha permitido acceder a un conjunto de espacios, códigos nativos y contactos que han enriquecido la investigación.
} 
ex-nadadores de primera categoría y personas que comenzaron a nadar siendo adultos y que de a poco fueron adquiriendo el nivel necesario para ingresar al equipo. La mayor parte de ellos son profesionales (abogados, contadores, médicos, arquitectos, ingenieros) comerciantes o estudiantes universitarios. También nos encontramos con amas de casa y jubilados. Si tomamos en cuenta esta composición socio-profesional inicial del equipo, podemos ubicar a sus miembros dentro del espectro de las clases medias, adscripción que será complejizada a lo largo del trabajo.

Una amplia cantidad de bibliografía entre la historia, sociología y antropología ha debatido sobre los criterios para distinguir entre las clases. Desde posiciones como las de Furbank (2005) que sostienen que hablar de clase media habla más de quien clasifica que del clasificado, entienden a las clases como ficción. Así, sostiene que:

Debemos desechar toda idea de que las clases realmente existen. No son cosas reales, sino ficciones o marcos imaginarios que las personas proyectan sobre los demás y cuya necesidad diferirá según la persona que haga la proyección y las razones que la impulsen a hacerla (FURBANK, 2005, p.31).

Que la clase sea entonces un concepto retórico (FURBANK, 2005, p. 18) suena tan atractivo como provocador. Aquí tomaremos esta idea como provocación e intentaremos "contestarla" desde la evidencia empírica producida en nuestro trabajo de campo. No negamos la dificultad de dar cuenta teórica y empíricamente de la existencia de las clases, especialmente de la clase media en este caso. Pero no rehusamos al desafío de ver el modo en que la experiencia de clase se actualiza en las prácticas de las personas con quienes estudiamos, y particularmente en este caso, en relación a la noción nativa de sacrificio.

Diversos trabajos se han hecho eco de esta preocupación de distintas maneras. Por un lado, encontramos una serie de autores (BOURDIEU, 1998; GIDDENS, 1983; WRIGHT, 1985) que configuran las principales tentativas de sistematizar y generalizar nociones de clase media desde la teoría social. Estos autores han elaborado esta pregunta en sus investigaciones tanto teóricas como empíricas, combinando distintas variables y ponderando algunas por sobre otras: ocupación, ingresos, trayectorias familiares, consumos culturales, etc. Aquí, reconocemos el esfuerzo de dichos autores por teorizar sobre la clase, pero sumamos a su vez la perspectiva subjetivista que toma en consideración el modo en que los actores se perciben a sí mismos. De este modo, encontramos una serie de investigaciones históricas y etnográficas que abordan a las clases sociales en general y a las clases medias, en particular no sólo como categoría de abordaje analítico, sino también como un modo efectivo al que apelan los actores para identificarse y reconocerse, y al que dotan de particulares contenidos a través de sus prácticas, experiencias e interpretaciones. (VISACOVSKY; GARGUIN, 2009). Por su parte, en el campo de los estudios sociales del deporte, la compleja relación entre deporte y clase social ha sido abordada desde diversas matrices teóricas. Algunas de ellas establecen asociaciones homológicas entre práctica deportiva y clase social, o afirman que las prácticas sociales en general y las deportivas y del tiempo libre en particular, se derivan inmediatamente de la posición de clase de los actores (BOURDIEU, 1990, 1993, 1998, 2000). Sin embargo, en Argentina, diversos trabajos empíricos han problematizado tal asociación enfocándose por un lado en mostrar la heterogeneidad social al interior de los espacios en que las prácticas deportivas se desarrollan (IULIANO, 2013; GARRIGA ZUCAL, 2013), y por otro, en los modos en que la diferenciación social se modula bajo lógicas específicas y en relación a capitales 
específicos que adquieren su valor en los distintos contextos de interacción. Esto no supone, como sostiene luliano (2013), renunciar a la interrogación por las posibles afinidades entre lo inculcado y lo practicado, sino que de lo que se trata es de problematizar las imputaciones exteriores que adjudican determinadas prácticas sociales a determinadas clases sociales. En este sentido, vale la pena rescatar los aportes realizados por Branz (2015), quien desde una perspectiva sensible al punto de vista de los actores, que no deja de lado la configuración social, histórica y geográfica del campo del rugby en la ciudad de La Plata, nos permite comprender al rugby como deporte vinculado a una distinción de clase, expresada en términos nativos en argumentos socioeconómicos, sostenidos por la geopolítica y componentes étnicos culturales.

Por otra parte, María Graciela Rodríguez (2013, p. 354) comparte la dificultad en abordar el fenómeno deportivo desde una perspectiva de clase, "[...] porque clase no solo es un concepto de difícil agarre, sino también porque el deporte se ha posicionado históricamente como transclasista y profundamente democrático".

Ahora bien, como se mostrará a lo largo del trabajo, al interior del grupo de nadadores master se pueden encontrar heterogeneidades que dan cuenta de la dificultad de establecer una relación entre clase social y ocupación. Sin embargo, tanto por los orígenes del club, como por la composición de su masa societaria, sí se puede establecer que hay un vínculo entre profesionales egresados en su mayoría de la Universidad Nacional de La Plata (UNLP) no sólo por la relación de sus miembros con la misma, sino también porque se encuentra una estimación positiva de los valores y saberes adquiridos en la universidad (HANG, 2014). El desafío del presente trabajo radica en comprender los modos en que a través de la práctica deportiva "los actores practican y definen su modo de pertenencia a la clase media" (VISACOVSKY; GARGUÍN, 2009, p. 13)

En este estado de la discusión, el presente trabajo aborda el vínculo entre deporte y clase social, a partir de la descripción y elaboración de algunos materiales de campo, en los que la noción nativa de sacrificio emerge como particularidad distintiva de la práctica. La puesta en relación de dicho concepto con las discusiones teóricas específicas permite reflexionar sobre los procesos de adscripción social y fronteras simbólicas que los grupos sociales construyen, en este caso, a partir de la puesta en contacto con una práctica deportiva.

\section{EL IMAGINARIO DEL SACRIFICIO VINCULADO A LA PRÁCTICA DEPORTIVA}

El equipo master del CULP participa dos veces por año de los campeonatos argentinos de natación master. Durante los cuatro días que duran dichas competencias, además de competir, los master suelen salir a bailar, a tomar algo, acostarse tarde, y dormir poco. A primera vista, podría resultar llamativo el hecho de que todos los nadadores acepten salir a bailar, o consumir bebidas alcohólicas, sabiendo que al día siguiente deben competir temprano. Sin embargo, los nadadores no se cuestionan esta práctica, sino que las salidas son parte de los torneos, tanto como el competir. Algunos hasta van a competir sin dormir, o llegan tarde y cansados a la competencia. De hecho, en un cumpleaños, Santi, un nadador de 25 años de edad, preguntó al resto de sus compañeros quiénes iban a participar del próximo torneo argentino que se iba a desarrollar en la ciudad de Rosario. "Ahí vamos todos, hay mucha joda, salimos todas las noches" sostuvo después. El resto de los nadadores, entre risas, estuvieron de acuerdo. Lucía, nadadora de 27 años, estudiante de abogacía, por su parte, añadió: "a mí 
me gustaría ir, pero este año no entrené nada. Ahora que no tengo auto, con el frío que hace, ni ganas de tomarme el micro". Santi le respondió: "no, claro, ni da, yo si no tengo auto no voy a entrenar ni en pedo".

Si tomáramos la escena anterior, en la cual un grupo de amigos, compañeros de un equipo de natación eligen las competencias en las cuales participar "por la joda", al tiempo que sostienen que "sin auto no van a entrenar", la pregunta por el sacrificio que planteamos al inicio del trabajo pareciera no tener sentido. Más si nos adentramos en el campo y consideramos otros escenarios en los cuales estos mismos actores asocian la práctica deportiva al sacrificio, veremos que vale la pena considerar su análisis. En un primer momento me llamaba la atención cómo a pesar de las salidas y la joda opera entre los master una ética del sacrificio. Sin embargo, como veremos más adelante esta ética en la cual conviven nociones de esfuerzo (económico y corporal) con imaginarios en torno a la joda y las salidas, adquiere un contenido específico.

No sólo entre los nadadores master, sino que también en los medios de comunicación encontramos un imaginario que asocia el sacrificio a la práctica deportiva ${ }^{5}$. Sin sacrificio no sería posible la experiencia sostenida (en el tiempo), ni menos aún el éxito dentro del campo deportivo. Ahora bien, a lo largo del trabajo de campo en distintos escenarios (competencias, entrenamientos y eventos sociales) los nadadores master ponen en juego una diversidad de sentidos en torno a la noción de sacrificio, que de manera analítica podemos reconstruir en dos dimensiones: por un lado, una dimensión económica, con la cual los nadadores asocian el sacrificio a trabajar y ahorrar para poder tener dinero para participar de las competencias y la práctica. Y por otro, una dimensión corporal, asociada al dolor, al sufrimiento, al agotamiento en los entrenamientos y/o en los días de competencia.

\section{3 “EL CLUB NO TE DA NADA”. EL SACRIFICIO Y LA PERTENENCIA AL CLUB.}

Para formar parte del equipo, los nadadores master deben abonar la cuota social del club, más el derecho por el uso de la pileta, y una suma destinada al fondo master, dinero destinado a pagar las inscripciones a las competencias y los viajes. Desde hace varios años, el club ha estado atravesando una situación financiera complicada ${ }^{6}$. A raíz de deudas millonarias con varios acreedores, los socios votaron en una asamblea del año 2013 que el club quede bajo una convocatoria de acreedores. Tras largos debates acerca de la situación del club y el modo de afrontar los pagos de las deudas entre la comisión directiva de ese momento y un grupo de socios opositores, a finales del 2014 la comisión directiva tomó la decisión de anticipar su salida, asumiendo la gestión del club nuevos directivos. Una de las primeras decisiones que tomaron fue no cobrar el uso de pileta a todos los deportistas del club7. Esta medida no fue bien recibida por los master, ya que como sostiene Carlos, un arquitecto de 50 años de edad, reconocido por sus compañeros como uno de los referentes del equipo:

[...]los master siempre tuvimos acceso libre a la pileta en verano, sin pagar temporada. $Y$ ahora estos dicen que nos la regalan. No nos regalan nada, si históricamente, en la cuota que pagamos nosotros, pagamos el derecho a ingresar a la pileta cuando

\footnotetext{
4 Por "joda" los nadadores refieren a las salidas nocturnas a boliches y bailes

5 Por ejemplo, la revista El gráfico titula una nota "Federico Grabich. Sacrificio Mundial". Allí, en una entrevista que realiza al nadador argentino clasificado para los Juegos Olimpicos de Rio de Janeiro 2016, este sostiene "odiar la pileta todas las mañanas". Pero este sacrificio, dice la nota, tiene su premio: brillar en los juegos Panamericanos. (GABRICH, 2015).

6 En la actualidad tiene una deuda de 20 millones de pesos

7 Además de la cuota del club, los socios deben pagar en la temporada de verano un monto extra, "la temporada", para poder ingresar a la pileta. En este caso, lo que sucedió fue que se eximió de pagar dicho monto a todos los deportistas del club.
} 
deseamos. Esa es una medida para los otros deportes. De hecho, en la reunión que tuvimos con la nueva comisión directiva ¿sabés lo que me preguntaron? ¡Si los master somos socios del club! No solo no saben que somos socios, tampoco saben que salimos terceros en el último sudamericano, no tienen ni idea de lo que hacemos, de cómo representamos al club (CARLOS,50 años).

Luego de un entrenamiento de verano, un pequeño grupo de nadadores decidió quedarse a almorzar en el club a la sombra de los árboles. Mientras almorzaban, llegó Susi, una nadadora master de 73 años de edad, cargando su bolso y una reposera, y quejándose porque "me querían hacer pagar el estacionamiento". Carlos le comentó que durante la temporada de verano, los fines de semana es obligatorio pagar estacionamiento. Marisa, nadadora de 50 años de edad de quien hablaremos en un próximo apartado, comentó: "yo por eso dejo el auto afuera. Si tengo que pagar estacionamiento cada vez que vengo a entrenar, no puedo". Susi, seguía cuestionando la medida y Marisa añadió:

[...]es así. Yo ya me cansé de pelear. Que el auto, que la revisación...Para entrar a la pileta, nos hicieron hacer un carnet nuevo, 20 pesos. En este club es así, uno paga y paga, y el club no te da nada. Venir a nadar en el verano es un sacrificio. Si no te gusta, andate a Poseidón, o Megatlón, que está todo lindo, moderno, limpito, pero claro, no tenés el equipo [...]. (MARISA, 50 años).

A raíz de las escenas anteriores, se pueden comenzar a vislumbrar los primeros sentidos asociados a la noción de sacrificio. Aquí vemos como ante una situación que los master califican como adversa, la apuesta por seguir formando parte del equipo del club es representada como sacrificada. Sacrificio que pasa no sólo por "pagar y pagar", sino fundamentalmente porque en esta relación no hay reciprocidad, ya que "el club no te da nada", a diferencia de a otros deportistas a quienes "le regalan la temporada", los master siguen aportando los valores que históricamente aportaron. La retribución que se les niega a los master no es sólo económica, sino que al mismo tiempo, es simbólica porque como sostiene Carlos "no tienen ni idea de lo que hacemos, de cómo representamos al club". De este modo, podríamos preguntarnos, como anticipamos más arriba, por qué vale la pena hacer el sacrificio. Y aquí, una de las claves de interpretación, puede entenderse en relación a la distinción que introduce Marisa al señalar que "si no te gusta, andate a Poseidón, o Megatlón". Ambas piscinas pertenecen a complejos privados, ubicados geográficamente a unas pocas cuadras del club. A pesar de que allí está "todo lindo, moderno, limpito", para los nadadores del club, ellos no tienen la calidad de equipo que tiene el club, un equipo que calificarán no sólo como exitoso en términos deportivos sino que, como veremos más adelante, los nadadores presentan a su equipo como "más unido, solidario, con una mejor calidad humana de sus miembros"8.

\section{4 "NO ES VERDAD QUE LOS MASTER TIENEN PLATA. MUCHOS HACEMOS BASTANTE SACRIFICIO PARA PODER PARTICIPAR". LA DIMENSIÓN ECONÓMICA DEL SACRIFICIO.}

Durante una entrevista realizada a Lidia, una nadadora master de 60 años de edad, comentó:

[...] los master no existíamos. Me cansé de escuchar, jlos master pueden porque tienen plata!, Imaginate, yo soy empleada pública, en un hospital, sin un cargo. № es verdad que los master tienen plata. Muchos hacemos bastante sacrificio para

8 HANG, 2013. 
poder participar. Tenemos las inscripciones más caras, nos pagamos los viajes a los torneos, nadie nos da un mango (LIDIA, 60 años).

En este relato, el sacrificio aparece emparentado a una cuestión económica. Hacer el sacrificio significa para Lidia trabajar para poder reunir la cantidad de dinero suficiente para pagar las inscripciones y viajar a los torneos. Es interesante pensar cómo Lidia se posiciona, frente a las versiones que sostienen que los master tienen plata, destacando su ocupación como empleada pública, sin cargo, que a su vez tiene que pagar las inscripciones más caras: estrategia discursiva a través de la cual refuerza esta idea de sacrificio.

Del mismo modo, Mariano, un nadador de 35 años de edad, ingeniero, afirma que: "El nadador master hace un esfuerzo mayor, es más valorable. No es lo mismo un nadador juvenil que un tipo que está trabajando, y que le dedica tiempo y esfuerzo a mantenerse compitiendo".

Al igual que para Lidia, para Mariano el sacrificio aparece asociado a la dimensión económica, a través del "tener que trabajar". A través de esta dimensión, que es a la vez moral, distingue a los master que tienen que trabajar, pero a su vez dedican tiempo y esfuerzo a seguir entrenando, de aquellos deportistas (juveniles o profesionales) que tienen tiempo (para entrenar y descansar). Esta clasificación nos permite considerar los modos en que los sentidos en torno al sacrificio aparecen atravesados por una nueva variable, la variable generacional, donde para los adultos, invertir tiempo y esfuerzo en entrenar redunda para Mariano en una acción "más valorable". Hasta aquí, entonces, podemos pensar cómo en torno a la noción de sacrificio y sus vínculos con las dimensiones económicas y generacionales, los nadadores comienzan a establecer categorizaciones que les permiten delimitar sentidos acerca de lo valioso, que seguiremos profundizando a continuación.

\section{5 "EN INVIERNO, ME CAGUÉ DE FRÍO, EN VERANO, EN LA PILETA DE AFUERA, SUCIA, LLENA DE MOSQUITOS, UN FRÍO DE CAGARSE, SIN AGUA CALIENTE EN EL VESTUARIO..." LA DIMENSIÓN CORPORAL DEL SACRIFICIO}

Tras finalizar el campeonato Sudamericano de natación master del año 2013, en el cual Marisa obtuvo el segundo puesto en las carreras de 100 y 200 metros pecho, visiblemente emocionada, me comentó:

Y bueno, la verdad es que yo hice un esfuerzo impresionante, un sacrificio... cuando no tenía auto, me tenía que tomar dos micros desde Berisso. En invierno, me cagué de frío, en verano, en la pileta de afuera, sucia, llena de mosquitos, un frío de cagarse, sin agua caliente en el vestuario...viste, todo en contra...y yo me había puesto en la cabeza que quería una medalla en el Sudamericano....y a veces estaba cansada, me dolía todo, pero venía igual (MARISA, 50 años de edad).

En el relato anterior se observa cómo otra vez el sacrificio aparece asociado al esfuerzo. Pero para Marisa, hacer un "esfuerzo impresionante" implica exponer el cuerpo a condiciones que ella califica como adversas, como las condiciones climáticas, la falta de infraestructura adecuada y el hecho de no tener agua caliente en los vestuarios. Menciona también el hecho de tener que tomarse dos micros ante la falta de vehículo propio, y finalmente resalta el cansancio y el dolor corporal. A diferencia de lo que Lucía y Santi sostenían más arriba, que "sin auto no van a entrenar ni en pedo", para Marisa el sacrificio pasa también por tomar dos micros, sacrificio que para ella es una condición para ganar una medalla, valiendo la pena porque es

9 Como sostuvo en la misma entrevista, frente a los nadadores juveniles que "no tienen otra obligación más que entrenar". 
una inversión que rendirá en el torneo. Exponer el cuerpo a condiciones adversas y al dolor, es la condición para obtener triunfos deportivos.

Ese dolor en la práctica, es compartido por varios deportistas. En un entrenamiento pude observar cómo Sofía, una joven nadadora de 22 años, se refería al trabajo realizado en el entrenamiento como "una tortura":

[...] me muero. ¡Esto es una tortura! Me quiero ir a casa. No me dan más los brazos" comentó Sofía con la respiración entrecortada. Marisa, alentándola, le respondió: "vamos Sofi. Es un último esfuercito y ya falta poco para el torneo". (SOFÍA, 22 años).

Vemos aquí entonces, como la dimensión corporal del sacrificio aparece en los entrenamientos, asociada a conceptos como el de "tortura", "esfuerzo", que si bien no son lo mismo, son condiciones que Marisa enuncia como necesarias para conseguir una medalla.

\section{6 "UNO SE ROMPE EL ORTO LABURANDO, HACES UN SACRIFICIO INMENSO...Y ESTOS...HACEN LO QUE SE LES CANTA Y NADIE DICE NADA". FRONTERAS SIMBÓLICAS CON LOS QUE NO SE SACRIFICAN"}

Mientras viajábamos al Campeonato Argentino de Natación master que tuvo lugar en el CENARD ${ }^{10}$, al pasar por la autopista por la villa $31^{11}$, Marcelo, un contador de 55 años de edad, comentó: "cómo está esto, un desastre". Y Gustavo, ingeniero, de 60 años, añadió: "encima los villeros hacen cualquier cosa y nadie dice nada, yo hago una ventana y tengo que pagar una multa y estos construyen lo que quieren, donde quieren. ¿Te das cuenta? Uno se rompe el orto laburando, haces un sacrificio inmenso...y estos...nadie dice nada...".

Marcelo asintió realizando un gesto con su cabeza. Sole, una nadadora de 26 años de edad, que viajaba sentada al lado mío en el asiento trasero, me miró sonriendo, y en voz baja me comentó: "anotá esto para tu tesis". Unos kilómetros más adelante, la conversación derivó hacia la situación actual del equipo de natación de primera categoría del club. Lautaro, un profesor de educación física de 35 años de edad que viajaba con nosotros, recordaba las épocas en que él era nadador juvenil como las "épocas de oro"12 del equipo, mientras que ahora sostiene que el equipo está en decadencia por la falta de nadadores y la mala calidad de los mismos. En este sentido, entiende:

[...] la decadencia se debe a que la natación es un deporte muy sacrificado, y los chicos ahora no quieren hacer el sacrificio. Nosotros íbamos todos los días, le hacíamos caso al entrenador. Nos iba bien, porque nos dedicábamos. Hacíamos podios en los (campeonatos) Argentinos. En cambio los pendejos ahora, quieren todo sin hacer ningún tipo de esfuerzo, se enojan si les va mal, pero no son capaces de hacer el sacrificio. Es lo mismo que hablábamos antes, de la sociedad, uno tiene que hacer sacrificios para progresar, y otros, tienen todo cortando una calle por ejemplo (LAUTANO, 35 años).

En esta escena, aparecen una serie de elementos que valen la pena poner en consideración. En primer lugar, porque los comentarios similares en los que se destaca el

10 Centro Nacional de Alto Rendimiento Deportivo

11 La Villa 31 es una villa miseria ubicada en la Ciudad de Buenos Aires en el barrio de Retiro. El asentamiento surgió en 1932 con el nombre de "Villa Desocupación". Según el censo realizado en el año 2009 por la Dirección General de Estadísticas y Censos del Gobierno de la Ciudad de Buenos Aires, para ese año se contabilizó un total de 7.950 hogares y 26.403 personas residentes en las Villas 31 y 31 bis. (ARGENTINA, 2009). 
sacrificio de unos en detrimento de lo que parecería el no sacrificio de otros, suelen ser muy comunes entre algunos nadadores del equipo master. En segundo lugar, porque muestra una clasificación moral, donde el sacrificio aparece otra vez asociado a la idea del trabajo, oponiéndose a aquellos que no se sacrifican. Aquí, alterizando con "los que hacen los que se le canta y nadie les dice nada", se ponen en juego distinciones sociales que permiten a la vez comprender la propia experiencia. Y tercero, porque cuando Sole dice "anotá esto para tu tesis", muestra una heterogeneidad de perspectivas al interior del grupo, donde se ve que ella no adscribe a ese tipo de narrativas.

Ahora bien, los que no se sacrifican, no son sólo aquellos que "no se rompen el orto laburando", sino que Lautaro establece una continuidad con los nadadores más jóvenes que quieren todo sin sacrificarse, motivo por el cual explica la decadencia del equipo de natación de primera. De este modo, el sacrificio vuelve a aparecer como condición necesaria para una idea de éxito (y progreso), erigiéndose como frontera de diferenciación social y simbólica con otros grupos sociales.

Por último, y al interior de la natación master, se producen alterizaciones con otros equipos, a los cuales los nadadores master del CULP representan como "menos unidos", a la vez que sostienen que "les pagan los viajes". Esta idea de amateurismo aparece a lo largo del trabajo de campo como un signo de identidad que los diferencia tanto de otros deportes como de otros equipos que no tendrían esta actitud desinteresada.

\section{EL SACRIFICIO ENTRE EL CUERPO, LO ECONÓMICO, LA MORAL Y “LA JODA”}

Hasta aquí, hemos analizado los diversos sentidos que los nadadores master del CULP le otorgan a la noción de sacrificio a través de dos claves analíticas: su relación con "Io económico" y "lo corporal". Dicho análisis, nos permitió observar cómo la noción de sacrificio, está atravesada por y configura representaciones de clase.

Podemos retomar la escena de la joda presentada más arriba, para preguntarnos cómo convive con la idea de sacrificio. Wacquant (2006) sostiene que el sacrificio constituye la moral propia de los boxeadores profesionales, constituyéndose en una ética que estaría englobada en tres mandamientos: no comer alimentos prohibidos, limitar la sociabilidad y no cometer intercambio sexual antes del combate. Ahora bien, en el caso de los master el sacrificio no pasaría por someterse a estas reglas, sino todo lo contrario. Antes del torneo los master salen a bailar, consumen alimentos prohibidos para los deportistas y bebidas alcohólicas. Mientras que el intercambio sexual antes de la competencia no estaría ni siquiera mal visto, tanto por los nadadores como por el entrenador. Entonces ¿de qué hablan los master cuando hablan de sacrificio? Si comparamos con el trabajo de Wacquant, pareciera entonces, que la noción nativa de sacrificio, operaría como una representación de un ideal que no todos cumplen. Sin embargo, el caso de los nadadores master reviste su especificidad, por lo cual el hecho de que los actores presenten su actividad como sacrificada, nos obliga a tomarla en serio y comprenderla en sus contextos específicos. Hacer el sacrificio significa para los master trabajar para poder reunir la cantidad de dinero suficiente para viajar a los torneos, pero también implica, a pesar de las obligaciones que la vida adulta y familiar trae consigo, poder organizarse para entrenar y competir, postergar algunos disfrutes en función de afrontar los gastos de los viajes a los torneos. A su vez hay un sentido de sacrificio que se asocia a lo corporal, al agotamiento, 
al sufrimiento, a la imposición de ir a entrenar más allá de estar cansado por las obligaciones diarias. Podemos también pensar al sacrificio en relación con el valor del amateurismo. En este sentido, el hecho de que varios nadadores reafirmen el valor de lo amateur implicaría una clasificación moral que hace del sacrificio una característica identitaria. Es decir que ser master, a diferencia de aquellos que cobran por competir, o aquellos a quienes les pagan los viajes, implicaría un mayor sacrificio. Varias veces los nadadores del CULP alterizan en sus discursos con nadadores de otros equipos, a los que sostienen que "les pagan los viajes", mientras que "nosotros gastamos y gastamos en pos de representar al club", como sostiene Gustavo, el ingeniero presentado más arribaResulta interesante destacar esta clasificación, ya que a través de ella la noción de sacrificio opera de una manera específica, en relación a los valores del amateurismo que los master destacan como positivos. Lo amateur se opone a lo profesional, a aquellas actividades que generan rédito económico. Como afirma Bourdieu:

\footnotetext{
[...] la teoría del amateurismo, que se deriva de una filosofía aristocrática del deporte como actividad desinteresada y gratuita, hace del deporte una práctica desinteresada, similar a la actividad artística. El deporte se concibe como una escuela de valentía y virilidad, capaz de formar el carácter y de inculcar la voluntad de vencer, pero de vencer según las reglas: es el fairplay, una disposición caballeresca totalmente opuesta a la búsqueda vulgar de la victoria a cualquier precio" (BOURDIEU, 1990, p. 198).
}

Lo amateur aparecerá constantemente en las entrevistas, no sólo como característica, sino principalmente como un signo de identidad, como aquello que los diferencia tanto de otros deportes como de otros equipos que no tendrían esta actitud desinteresada.

A través del trabajo con el cuerpo entonces, y durante los entrenamientos compartidos cuatro veces por semana, los master incorporan, al tiempo que producen, una ética del sacrificio que opera generando moralidades y principios de visión y clasificación del mundo social. A partir de los sentidos otorgados al sacrificio, los master clasifican y se distinguen de otros, y se identifican como grupo.

\section{REFLEXIONES FINALES. ¿ES POSIBLE PENSAR AL DEPORTE COMO UN ESPACIO DONDE EL SACRIFICIO APARECE COMO PARTICULARIDAD DE CLASE?}

Una serie de investigaciones académicas entre las que se destacan las de Visacovsky (2014) abordan la narrativa del sacrificio como particularidad de las clases medias. De este modo, el proyecto inicial de este trabajo buscó insertarse en esta línea para intentar comprender, a partir del estudio de una práctica deportiva, los vínculos o continuidades que operan entre la idea del sacrificio presente en la natación master y en las representaciones de un sector de las clases medias platenses. Si como sostiene Archetti (2003), el deporte se nos presenta como un espacio privilegiado para observar trazas relacionales entre lo macro y lo micro, podemos preguntarnos si el campo de la natación master puede constituirse como espacio donde el sacrificio aparece como particularidad de clase (media). Visacovsky (2014) se concentra en los sentidos nativos del sacrificio en las narrativas de clase media, observando una relación de este último con las nociones de trabajo duro y esfuerzo. Lo interesante de esta idea consiste para el autor en el modo en que adquieren sentido en una dimensión temporal, en el sentido de que el sacrificio se orienta al futuro, y el presente tiene sentido solo en relación a una esperanza de éxito posterior. En este punto podemos establecer una relación con los sentidos 
que los master le otorgan al sacrificio, como acción que vale la pena porque luego rinde en las competencias. Sin embargo, si bien se pueden encontrar continuidades entre el lenguaje del sacrificio presentado por el autor y el lenguaje del sacrificio en el deporte, creemos que la relación con la noción de clase media no agota la explicación de por qué los nadadores se sacrifican, o sostienen hacerlo, ni la relación instrumental que hubiera entre sacrificarse y obtener logros deportivos. En este sentido, diversas investigaciones en el campo de los estudios sociales del deporte, también remarcan la continuidad existente entre deporte y sacrificio, y el sistema de clasificaciones morales que se establece en torno a él. Rodríguez A. (2013) sostiene que entre los "fierreros" se representan a su cuerpo como un producto construido a base de la voluntad y el esfuerzo individual, de su sacrificio físico, a través del cual trazan una distancia de aquéllos que no logran lo que se proponen porque no se valoran ni tienen voluntad. Para el caso del rugby, Branz (2014) sostiene que a través de la noción de sacrificio se construye honor y masculinidad, distanciándose así de otros deportes y sectores sociales.

Por lo tanto, podemos sostener, que en el caso de los master, la idea de sufrir y sacrificarse en el entrenamiento, funciona de hecho como una apuesta a futuro, como una inversión que tendrá sus frutos en la competencia, pero además y fundamentalmente, como marca de superioridad moral, que hermana a los nadadores que han compartido y transitado una experiencia de sacrificio en el agua, y en un club que atraviesa una situación de adversidad, que los distingue y construye fronteras simbólicas no sólo con otros equipos de natación, sino también con otros deportistas, con otras épocas e inclusive con otros sectores de la sociedad que según los nadadores no se sacrifican como ellos.

A través del sacrificio que implica la búsqueda de la medalla, los nadadores master consruyen una marca identitaria a través de la cual evalúan moralmente lo valioso y lo meritorio, entrando en juego una distinción con otros espacios y otros agentes del mundo social ${ }^{13}$. Distinción que vale la pena seguir explorando, para comprender el modo en que a través de ella se juegan maneras de comprender el mundo social, valores, moralidades, relaciones de poder, jerarquías grupales, distinciones (intragrupales e intergrupales), jerarquías etarias, y de clase.

\section{REFERÊNCIAS}

ALABARCES, Pablo; GARRIGA ZUCAL José; MOREIRA, Maria.Verónica. La cultura como campo de batalla: fútbol y violencia en la Argentina. Versión Estudios de Comunicación, Política y Cultura, $n$. 29, p. 2-20, abr. 2012.

ARCHETTI, Eduardo. Masculinidades: fútbol, tango y polo en la Argentina. Buenos Aires: Antropofagia. 2003.

ARGENTINA. Ministério da Hacienda. Censo de hogares y población: villas 31 y 31 bis, Ciudad de Buenos Aires 2009. Disponible em: <https://www.estadisticaciudad.gob.ar/eyc/wp-content/ uploads/2015/04/villa 31 y 31 bis 2009 abril.pdf>. Acceso en: 16 mar. 2017.

BOURDIEU, Pierre. ¿Cómo se puede ser deportista? In: Bourdieu, Pierre. Sociología y cultura. México: Grijalbo, 1990. p. 193-213.

13 Esto no quiere decir que el sacrificio marque rígidamente una frontera de clase, sino que opera como (una) categoría a través de la cual los nadadores establecen alterizaciones y categorizaciones sociales a través de las cuales se piensan a ellos mismos y a los otros. 
BOURDIEU, Pierre. Deporte y clase social. In: Barbero, Martín y otros. Materiales de sociología del deporte. Madrid: La Piqueta, 1993. p. 57-82.

BOURDIEU, Pierre. Programa para una sociología del deporte. In: Bourdieu, Pierre. Cosas dichas. Barcelona: Gedisa, 2000. p. 173-184.

BOURDIEU, Pierre. La distinción: criterios y bases sociales del gusto. Bogotá: Santillana. 1998.

BRANZ, Juan. Deporte y masculinidades entre sectores dominantes de la ciudad de La Plata Estudio sobre identidades, género y clase. Tesis (Doctorado en Comunicación) - Facultad de Periodismo y Comunicación Social, Universidad Nacional de La Plata, La Plata, 2015. Disponible en: $<$ http://sedici.unlp.edu.ar/handle/10915/44890>. Acceso en: 17 mar. 2017.

BRANZ, Juan; GARRIGA ZUCAL, José; MOREIRA, María Verónica. Deporte y ciencias sociales: claves para pensar las sociedades contemporáneas. La Plata: EDULP, 2013.

FURBANK, Philippe. Un placer inconfesable o la idea de clase social. Buenos Aires: Paidos, 2005.

GABRICH, Federico. Federico Grabich: sacrificio mundial. Entrevista concedida a Martín Estévez. 14 nov. 2015. Disponible en: <http://www.elgrafico.com.ar/2015/11/14/C-8568-federico-grabich-sacrificiomundial.php>. Acceso en: 9 mar. 2017.

GARRIGA ZUCAL, José. Entre aguantadores y picantes. Violencia y sectores populares en una hinchada de fútbol argentina. In: DEPORTE y ciencias Sociales: claves para pensar las sociedades contemporáneas. La Plata: Paidos, 2013. p. 169-199.

GIDDENS, Anthony. La estructura de clases en las sociedades avanzadas. Madrid: Alianza, 1983.

HANG, Julia. Ah, ahora vas a estudiar a los traidores: reflexiones sobre las categorías identitarias operantes en torno a la práctica de la natación master. In: CONGRESO ARGENTINO DE EDUCACIÓN FÍSICA Y CIENCIAS, 10., 2013, La Plata. Memoria Académica. Disponible en: <http:// www.memoria.fahce.unlp.edu.ar/trab eventos/ev.3263/ev.3263.pdf>. Acceso en: 9 mar. 2017.

HANG Julia; BRANZ, Juan: "Acá nosotros nos rompemos el culo": los sentidos del sacrificio entre nadadores y jugadores de rugby en la ciudad de La Plata. 2014. Disponible en: <http://www.11caas. org/conf-cientifica/comunicacionesActasEvento.php>. Acceso en: 9 mar. 2017.

IULIANO Rodolfo . Fronteras simbólicas y diferenciación social en torno a la práctica de golf. In: BRANZ, Juan; GARRIGA ZUCAL, José; MOREIRA, María Verónica. Deporte y ciencias sociales: claves para pensar las sociedades contemporáneas. La Plata: EDULP, 2013. p. 35-70.

RODRIGUEZ, Alejandro. Ellos hacen fierros. La construcción del cuerpo masculino en los gimnasios porteños. In: BRANZ, Juan; GARRIGA ZUCAL, José; MOREIRA, María Verónica. Deporte y Ciencias Sociales: claves para pensar las sociedades contemporáneas. La Plata: EDULP, 2013. p. 293-312.

RODRIGUEZ, María Graciela. Conclusiones: "¿qué es un campo y tu me lo preguntas?". In: BRANZ, Juan. GARRIGA ZUCAL, José; MOREIRA, María Verónica. Deporte y ciencias sociales: claves para pensar las sociedades contemporáneas. La Plata: EDULP, 2013. p. 337-362.

VISACOVSKY, Sergio. Crisis, lenguaje del sacrificio y la narrativa de origen de la clase media en la argentina. In: CONGRESO ARGENTINO DE ANTROPOLOGÍA SOCIAL, 11., 2014, Rosario. [Anales...] Disponible en: <http://www.11caas.org/conf-cientifica/comunicacionesActasEvento.php $>$. Acceso en: 16 mar. 2017. 
VISACOVSKY, Sergio; GARGUIN, Enrique. Moralidades, economías e identidades de clase media: estudios históricos y etnográficos. Buenos Aires: Antropofagia, 2009.

WACQUANT, Löic. Entre las cuerdas: cuadernos de un aprendiz de boxeador. Buenos Aires: Siglo XXI, 2006.

WRIGHT, Eric Olin. ¿Qué hay de «medio» en la clase media? Madrid: Zona Abierta, 1985. p. 105-149. 
Apoio:

CONICET

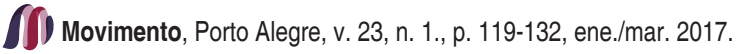

